PUBLIC HEALTH RESEARCH

\title{
Support of smoking restriction in public areas among adolescents in Malaysia-The findings from Tobacco and E-Cigarette Survey among adolescents in Malaysia (TECMA)
}

\author{
Kuang Hock Lim*, Pei Pei Heng, Hui Li Lim, Yoon Ling Cheong, Chee Cheong Kee, Sumarni Mohd Ghazali \\ and Jia Hui Lim
}

Institute for Medical Research, Jalan Pahang, Kuala Lumpur,Malaysia.

*For reprint and all correspondence: Kuang Hock Lim, Institute for Medical Research, Jalan Pahang, Kuala Lumpur, Malaysia.

Email: keelimkota@yahoo.com

ABSTRACT

$\begin{array}{ll}\text { Introduction } & \text { Adolescents are the future generation, and their support for smoke-free policies } \\ \text { might create momentum for future stringent smoke-free initiatives. This study } \\ \text { aimed to determine the levels and factors associated with support for smoking } \\ \text { in public areas among Malaysian school-going adolescents aged 10-19 years. } \\ \text { The data were derived from the Tobacco and E-cigarettes among adolescents in } \\ \text { Malaysia (TECMA), which employed the cross-sectional study design and } \\ \text { multistage sampling to select the representative samples of school-going } \\ \text { adolescents. Data was obtained through self-administered of pre-validated } \\ \text { questionnaire. Descriptive study, cross-tabulation and multivariable analysis } \\ \text { were used for analysis. } \\ \text { Majority of respondents supported smoking restriction in public areas (86.3\%, } \\ \text { 95 CI 85.4-87.1). The proportion and likelihood of support of smoke-free } \\ \text { initiative were higher among respondents with better knowledge of the harmful } \\ \text { effects of second-hand smoke (SHS), been taught in school about the health } \\ \text { effects of smoking, older age group (16-19 years), female, those students } \\ \text { schooling in urban areas, Malay and other Bumiputras from Sabah and Sarawak. } \\ \text { However, current smokers and ECV users were less likely to support smoke- } \\ \text { free initiatives in public areas. } \\ \text { The level of support for smoke-free initiative in public areas was high among } \\ \text { youths in Malaysia, and this might offer promising prospects to expand the non- } \\ \text { Conclusions } \\ \text { smoking areas to more public areas in the future. } \\ \text { Smoke-free public area - level of support - school-going adolescent - smoking } \\ \text { status - TECMA. }\end{array}$

Article history:

Received: 29 November 2020

Accepted: 8 June 2021

Published: 1 March 2022 


\section{INTRODUCTION}

Exposure to second-hand smoke contributed to numerous health problems across the population, including exacerbation of bronchial asthma, respiratory infections, and sudden infant death syndrome (SIDS) among infants and children, and increased risk of coronary heart disease, stroke, and lung cancer among adults. ${ }^{1,2}$ A total of $1 \%$ of the Global Burden of Diseases was attributed to secondhand smoke (SHS) exposure. ${ }^{2}$ As a result, the World Health Organisation (WHO) had announced the article on smoke-free provision in Framework Convention on Tobacco Control (FCTC) ${ }^{3}$ which had been rectified by 163 countries globally, including Malaysia.

As a signatory of FCTC, the Ministry of Health $(\mathrm{MOH})$ Malaysia had introduced smoke-free areas through the provision of Control of Tobacco Product Regulation $2004^{4}$ which had been amended from time to time to expand the non-smoking public areas. It aims to protect non-smokers from the SHS exposure and to de-normalise the smoking behaviours among Malaysian society. ${ }^{5}$ The enforcement activities at gazetted smoke-free public areas and the introduction of the "Young Doctor Programme". ${ }^{6}$ had been implemented to ensure the stipulated objectives in the smoke-free policies were achieved. However, various studies had revealed that public support towards smoke-free policies is the pre-requisite to achieve the target of smoke-free policies, especially for a democratic country like Malaysia. ${ }^{7}$ Public support will enable the implementation of any government policy together with its enforcement without much resistance. Conversely, lack of public support will leave the lawmakers more susceptible to the influence of the tobacco advocator. Therefore, it reduces the efficacious of the implementation of smoke-free policies. ${ }^{7-9}$.

Given the youth is the future generation who will determine the future progress of tobacco control in the society and country, several studies have been carried out to assess the level of support among youths toward smoke-free policy in public area. Studies revealed that the level of support was between $40-85 \%$ depending on the smoke-free locality. ${ }^{10-11}$ In addition, the studies also showed that male, smoking status, perception of harmful of tobacco and health effects of second-hand smoke exposure, and tobacco de-normalisation beliefs, were significantly associated with the support for smoke- free policy. ${ }^{10}$ However, those studies were carried out in countries with different anti-smoking legislation, social norm and social-demographic backgrounds. Therefore, the findings might not be applicable to Malaysia. In addition, the study on the level of support in Malaysia were mainly focused on adults without much attention to adolescents. The youth is the future generation who will determine the future progress of tobacco control in the country.
Therefore, the information on the support of smokefree policy among youths is of paramount importance as it will assist the policymaker in formulating appropriate measures in tobacco control in Malaysia.

The present study aimed to investigate (i) adolescent support for tobacco-free policy (SFP) in Malaysia, and to investigate (ii) the associations between socio-demographic and other smokingrelated characteristics with the support of smokefree smoking policies.

\section{METHODS}

Data were derived from a nationwide school-based study "Tobacco \& E-Cigarette Survey Among Malaysian Adolescents" (TECMA) in 2016. A cross-sectional study design and multiple-stage cluster sampling was employed to select a representative sample of upper primary and secondary Malaysian school-going students aged from 10 to 19 years old. Fifteen states in Malaysia were included in the first strata, while urban and rural areas for each state was considered as the second strata. The primary sampling unit (school) was selected through proportionate sampling to size based on the latest sampling frame of upper primary and secondary school enrolment provided by the Ministry of Education (MOE), Malaysia. Subsequently, the classes as the secondary sampling unit from each chosen school were selected via simple random sampling. All students from the selected classes were included as participants of the study. In total, 138 schools were selected (i.e. 82 urban and 56 rural schools). A total of 13,980 respondents were required for the study based on an estimated prevalence of 3\% e-cigarette users among adolescents in Korea. ${ }^{12}$ type one error of 0.05 , with a design effect to account for any cluster effects among students in the classes, the precision rate of $1.5 \%$ and the expected non-response rate of $20 \%$. Detailed illustration of the study can be obtained from TECMA study. ${ }^{13}$

\section{Measures}

An active, informed consent approach was used to obtain permission from the parents/guardians of the selected respondents. Specifically, the informed consent forms and illustration of study were distributed to parents/guardians of the selected respondents via the school administration, in which the illustration consisted of the study objectives, their son/daughter's participation were based on voluntary basis, their anonymity was assured, and the data were only used for research purposes. Parents/guardians were asked to return the informed consent form if they would allow their child to participate in the study. Only selected respondents who consented by their parents/guardian could participate in the study. In addition to consent from students' parents/guardians, selected respondents 
were also asked to sign an additional consent form if they agreed to participate in the study. Data collection was carried out in a designated area identified by school administrators during the school day. To avoid biases, no schoolteachers and staffs were allowed to be present during the data collection session.

Research team members provided the details on the study prior to questionnaire completion. The briefing session has delivered clear information on the study objectives, contents of the questionnaire, and assurance that all participations were voluntary, i.e. students could skip any item(s) on the survey. A validated standard questionnaire adapted from the Global Youth Tobacco Survey (GYTS) was used in the study, which consisted of five sections: (a) social-demographic (i.e., age, gender, standard/form of study [i.e., upper primary, lower secondary, upper secondary], ethnicity, daily school pocket money); (b) tobacco use (e.g., current use status, age of initiation); (c) e-cigarette use (i.e., current status, number of quitting attempts); and (d) shisha (i.e., current use status, age of initiation). The study protocol was approved by Malaysia's MOE, $\mathrm{MOH}$, and the State Education Department; ethical approval was granted by the Medical Research and Ethics Committee of Malaysia's $\mathrm{MOH}$.

The dependent variable "support for smoke-free measures in public place" was measured using the item, "are you in favour of banning smoking inside enclosed public places (such as shops, restaurants, bus, taxi, train, school, playgrounds, gymnasium, sports centre and shopping malls)? Respondents were required to answer either "Yes" and "No". Independent variables in the study were socio-demographic variable, namely gender, form of study (i.e., upper primary, lower secondary, upper secondary), ethnicity (i.e., Malay, Chinese, Indian, Bumiputra
Sabah, and Bumiputra Sarawak), locality (i.e., urban/rural), smoking status (i.e., current smoker: smoked at least once in the last 30 days). Their knowledge on harmful health effect to SHS (Yes/No), exposed to SHS (at home and other places than home) E-cigarette user (Yes/No).

Data analysis

Prior to analysis, data were cleaned and weighted based on the study design and non-response rate according to the school enrolment for upper primary and secondary schools in the year 2014. Descriptive statistics were used to describe respondents' demographic characteristics while the Chi-square analysis was used to determine the association between "support for restrict smoking in public areas," and all categorical independent variables Multivariable logistic regression (MLR) was conducted to identify factors associated with support for smoke-free policy. The effect of each independent variable on the dependent variable was determined after adjusting for the influence of other confounding factors. All independents in the final model were examined for possible all two-way interactions, and a p-value exceeding 0.05 indicated that no interaction was detected. All statistical analyses were run at a $95 \%$ CI using SPSS software version 20 (Complex sampling method).

\section{RESULTS}

The response rate for the study is $87.9 \%$. From the total number of 13,250 students who responded, a nearly equal proportion of male and female subjects was observed. A similar pattern of same proportion was also found among the schooling areas of respondents. Two-third of respondents were formed Malay descents and approximately one-fourth of adolescents aged 16-19 years old (Table 1).

Table 1 Social-demographic characteristic of respondents

\begin{tabular}{lrrr}
\hline Variable & Estimated population & sample & $\%$ \\
\hline Gender & & & \\
$\quad$ Male & 1881131 & 6582 & 51.1 \\
Female & 1803629 & 6554 & 48.9 \\
Age group (years) & & & \\
12 and less & 1369393 & 4138 & 37.2 \\
13-15 & 1434842 & 5278 & 38.9 \\
16-19 & 880523 & 3726 & 27.9 \\
Ethnicity & & & \\
-Malay & 2433437 & 9243 & 66.1 \\
Chinese & 477956 & 1764 & 13.0 \\
Indian & 213674 & 748 & 5.8 \\
Bumiputra Sabah & 211781 & 545 & 5.7 \\
Bumiputra Sarawak & 195558 & 447 & 5.7 \\
Others & 147095 & 385 & 4.0 \\
Strata & & & \\
Urban & 1677958 & 7689 & 45.3 \\
Rural & 2006801 & 5448 & 54.5
\end{tabular}


Tobacco Smoking Status

$\begin{array}{lrrr}\text { Yes } & 524231 & 1807 & 14.2 \\ \text { No } & 3160528 & 11329 & 85.8\end{array}$

Majority of the school-going adolescents $(86.3 \%)$ expressed their support for smoke-free regulation in public areas, and the proportion was significantly higher among adolescents with good knowledge on the harmful effects of SHS (90.3 vs $51.0 \%, \mathrm{p}<0.001)$, and those who had been taught in school about the harmful effects of tobacco $(90.5 \%$ vs $66.5 \%, p<0.001)$. In addition, the level of support for smoke-free regulation in public areas also significantly higher among the female $(89.4 \%$ vs $83.2 \%, \mathrm{p}<0.001)$, adolescents schooling in urban areas, adolescents aged 16-19 years, those who exposed to SHS at home and places other than home. However, the proportion of current smokers and ECV users who supported smoke-free regulation in public areas was lower compared to non-smokers and non-ECV user. Similar pattern was also observed in multivariable analysis, in which the likelihood of support for smoke-free regulation in public areas was higher among respondents with higher knowledge of SHS (AOR 5.75, 95\% CI $4.70 * 7.03)$, and those who had been taught in school on danger of tobacco (AOR 2.43, 95\% CI 2.03-2.89) (Tables 2 and Table 3 ).

Table 2 Support for smoke free policy in Public Areas among School Going Adolescents in Malaysia.

\begin{tabular}{|c|c|c|c|c|c|c|}
\hline \multirow[t]{3}{*}{ Variable } & \multicolumn{6}{|c|}{ Support for smoke free in public areas } \\
\hline & \multirow{2}{*}{$\begin{array}{l}\text { Estimated } \\
\text { population }\end{array}$} & sample & $\%$ & \multicolumn{2}{|c|}{$95 \% \mathrm{CI}$} & \multirow[t]{3}{*}{$\mathrm{p}$ value } \\
\hline & & & & Lower & Upper & \\
\hline Overall & 3168437 & 11635 & 86.3 & 85.4 & 87.1 & \\
\hline \multicolumn{7}{|l|}{ Gender } \\
\hline Male & 1559678 & 5504 & 83.2 & 81.9 & 84.4 & \multirow[t]{2}{*}{$<0.001$} \\
\hline Female & 1608758 & 5801 & 89.4 & 88.4 & 90.4 & \\
\hline \multicolumn{7}{|l|}{ Locality } \\
\hline Urban & 1421043 & 6646 & 84.9 & 83.7 & 86.0 & \multirow[t]{2}{*}{0.003} \\
\hline Rural & 1747393 & 4719 & 87.4 & 86.2 & 88.5 & \\
\hline \multicolumn{7}{|l|}{ Age groups (Years) } \\
\hline 12 and younger & 1115839 & 3302 & 81.9 & 80.4 & 83.3 & \multirow[t]{3}{*}{$<0.001$} \\
\hline $13-15$ & 1256464 & 4694 & 87.6 & 86.1 & 89.0 & \\
\hline $16-19$ & 796132 & 3369 & 90.8 & 89.6 & 91.8 & \\
\hline \multicolumn{7}{|l|}{ Ethnicity } \\
\hline Malay & 2164315 & 8286 & 89.2 & 88.3 & 90.1 & \multirow[t]{6}{*}{$<0.001$} \\
\hline Chinese & 344934 & 1262 & 72.3 & 69.5 & 74.9 & \\
\hline Indian & 157605 & 573 & 73.9 & 69.3 & 79.0 & \\
\hline Bumiputra Sabah & 198543 & 508 & 94.3 & 91.7 & 96.1 & \\
\hline Bumiputra Sarawak & 179539 & 407 & 90.0 & 86.4 & 92.7 & \\
\hline Others & 122723 & 327 & 87.9 & 79.0 & 87.8 & \\
\hline \multicolumn{7}{|c|}{ SHS Exposure in the house } \\
\hline Yes & 1697795 & 6042 & 90.3 & 89.2 & 91.2 & \multirow[t]{2}{*}{$<0.001$} \\
\hline No & 1469905 & 5320 & 82.1 & 80.7 & 83.3 & \\
\hline \multirow{2}{*}{\multicolumn{7}{|c|}{$\begin{array}{l}\text { SHS Exposure other than in the } \\
\text { house }\end{array}$}} \\
\hline & & & & & & \\
\hline Yes & 1233901 & 4121 & 89.0 & 87.7 & 90.2 & \multirow[t]{2}{*}{$<0.001$} \\
\hline No & 1934535 & 7241 & 84.6 & 83.5 & 85.7 & \\
\hline \multicolumn{7}{|l|}{ Current Smoker } \\
\hline Yes & 337833 & 1162 & 82.1 & 78.8 & 84.9 & \multirow[t]{2}{*}{0.002} \\
\hline No & 2703625 & 9789 & 86.6 & 85.7 & 87.5 & \\
\hline \multicolumn{7}{|l|}{ E-Cigarette User } \\
\hline Yes & 240629 & 856 & 80.8 & 77.1 & 84.0 & \multirow[t]{2}{*}{$<0.001$} \\
\hline No & 2583112 & 9274 & 87.0 & 86.0 & 87.8 & \\
\hline \multicolumn{7}{|c|}{$\begin{array}{l}\text { Been taught in school about } \\
\text { harmful of tobacco }\end{array}$} \\
\hline Yes & 2530782 & 8962 & 90.5 & 89.7 & 91.3 & \multirow[t]{2}{*}{$<0.001$} \\
\hline No & 311317 & 1192 & 66.5 & 63.4 & 69.4 & \\
\hline
\end{tabular}


Tobacco smoke is harmful

\begin{tabular}{lrrrrrr} 
Yes & 2974221 & 10719 & 90.3 & 89.6 & 91.1 & $<0.001$ \\
No & 194215 & 646 & 51.0 & 47.3 & 54.7 & \\
\hline
\end{tabular}

Table 3 Multiple Logistic regression to determine associated factors with support of Smoke Free Policy among school-going adolescents in Malaysia.

\begin{tabular}{|c|c|c|c|c|c|}
\hline \multirow[t]{2}{*}{ Variables } & \multirow[t]{2}{*}{$\beta$} & \multirow{2}{*}{$\begin{array}{c}\text { Standard } \\
\text { error (S.E) }\end{array}$} & \multirow{2}{*}{$\begin{array}{c}\text { Adjusted Odd } \\
\text { Ratio } \\
\text { (AOR) }\end{array}$} & \multicolumn{2}{|c|}{$95 \% \mathrm{CI}$} \\
\hline & & & & Lower & Upper \\
\hline \multicolumn{6}{|l|}{ Gender } \\
\hline Male & & & Ref & & \\
\hline Female & 0.386 & 0.088 & 1.37 & 1.14 & 1.64 \\
\hline \multicolumn{6}{|l|}{ Locality } \\
\hline Urban & & & Ref & & \\
\hline Rural & -0.166 & 0.083 & 0.85 & 0.72 & 1.01 \\
\hline \multicolumn{6}{|l|}{ Age groups (Years) } \\
\hline 12 and younger & & & Ref & & \\
\hline $13-15$ & 0.826 & 0.104 & 1.64 & 1.35 & 1.99 \\
\hline $16-19$ & 0.599 & 0.099 & 2.08 & 1.70 & 2.55 \\
\hline \multicolumn{6}{|l|}{ Ethnicity } \\
\hline Malay & 1.152 & 0.101 & 2.61 & 2.13 & 3.29 \\
\hline Chinese & & & Ref & & \\
\hline Indian & 0.239 & 0.159 & 1.26 & 0.92 & 1.74 \\
\hline Bumiputra Sabah & 1.693 & 0.252 & 4.85 & 2.99 & 7.88 \\
\hline Bumiputra Sarawak & 1.363 & 0.219 & 3.00 & 1.98 & 4.54 \\
\hline Others & 0.958 & 0.219 & 2.35 & 1.31 & 3.67 \\
\hline \multicolumn{6}{|c|}{ SHS Exposure in the house } \\
\hline Yes & -0.057 & 0.112 & 0.93 & 0.75 & 1.16 \\
\hline No & & & Ref & & \\
\hline \multicolumn{6}{|c|}{$\begin{array}{l}\text { SHS Exposure other than in } \\
\text { the house }\end{array}$} \\
\hline Yes & 0.528 & 0.099 & 1.65 & 1.34 & 1.16 \\
\hline No & & & Ref & & \\
\hline \multicolumn{6}{|l|}{ Current Smoker } \\
\hline Yes & & & Ref & & \\
\hline No & 0.383 & 0.179 & 1.47 & 1.04 & 2.12 \\
\hline \multicolumn{6}{|l|}{ E-Cigarette user } \\
\hline Yes & & & Ref & & \\
\hline No & 0.443 & 0.169 & 1.47 & 1.01 & 2.14 \\
\hline \multicolumn{6}{|c|}{$\begin{array}{l}\text { Been taught in school about } \\
\text { harmful of tobacco }\end{array}$} \\
\hline Yes & 0.998 & 0.084 & 2.43 & 2.05 & 2.89 \\
\hline No & & & Ref & & \\
\hline \multicolumn{6}{|c|}{ Tobacco smoke is harmful } \\
\hline Yes & 1.129 & 0.085 & 5.75 & 4.70 & 7.03 \\
\hline No & & & Ref & & \\
\hline
\end{tabular}

\section{DISCUSSION}

The research presented in this paper was the first study which reported on school-going adolescents' support for smoke-free regulation in public areas. The study revealed that majority of the school-going adolescents were supportive of smoke-free in public areas. Our proportion was higher than the figure of $54.1 \%$ as reported in Hong Kong , ${ }^{11} 59 \%$ in New Zealand , ${ }^{14}$ and globally of $74 \% .{ }^{15}$ However, it is lower than $91.4 \%$ reported by Erguder et al. among youths in Turkey. ${ }^{16}$ The higher support observed in the current study was encouraging, and probably due to a longer duration of implementation of public smoke-free laws in Malaysia compared to those studies. True enough, previous studies revealed that the level of support for smoke-free initiative increased in tandem with the period of policy implementation. In addition, these findings might be due to the comprehensive initiatives implemented by various stakeholders, including health promotion by both of the healthcare practitioners and the MOE in preventing smoking initiation among adolescents in Malaysia since the recent years. However, this should be thoroughly investigated in future studies. 
In accordance with the finding by Lazuras and Chen among youth in Greece and Hong Kong, respectively. ${ }^{10-11}$ Our study found that the odds of supporting smoke-free initiatives among those with knowledge on harmful effects were more than five times higher than their counterpart who possessed a lower knowledge level. Our finding was imperative as the overall health beliefs, and health-related behaviours were focused in the present study. The anticipation of the adverse health impacts that might harm the surrounding people, which does not only come from their own smoking behaviour but also via SHS exposure, was being assessed in the present study. Hence, it provided a more relevant and practical information on the support for smoke-free policies as the prediction on both the health consequences on self and surrounding people were taken into account following the smoking and SHS exposures.

Current smokers and ECV users were less likely to support smoke-free initiatives in public place, and the finding was congruent with the previous studies which reported that nonsmokers were the most supportive group for smoke-free ${ }^{10-11}$ initiatives. Smokers apprehend smoke-free policies as a barrier for them to smoke without restriction in all public localities. In addition, active smokers could perceive the distress situation that they might experience once the smoke-free legislation is enforced, thus decrease their support on smoke-free policies. Moreover, in order to justify and rationalise their smoking habit, smokers were prone to underestimate the health impacts of SHS exposure towards non-smokers, besides recognising smoking as an individual's right. Some of them might even presume that SHS is less hazardous compared to the emission of gases from motor vehicles. Festinger's cognitive dissonance theory postulates ${ }^{17}$ that human has the inclination to adjust the regularity and consistency between one's perceptions, belief and behaviours. However, whenever the inconsistency exists (e.g. when smokers realise smoking is harmful somehow wish to continue the habit), they will make an adjustment in their own belief and perception (e.g. falsify the negative consequences into the positive ones) or even through behavioural modification (e.g. quit smoking) in order to restore the equity. Nevertheless, changing one's perception was found to be easier compared to behavioural change; hence smokers are more likely to espouse the risk-minimising beliefs which then post an influence on them to oppose the smoke-free policies. ${ }^{17}$

The associations between perceptions of the harmful effects of smoking and support for tobacco control policies in our study were also congruent with previous research among adolescents. ${ }^{10-11}$ which profoundly suggested that delivering the message on the health harm of smoking may increase support for smoke-free policy. The finding might be explained by a health belief model that suggested the perceived susceptibility and severity of specific behaviour might influence human perception. ${ }^{18}$ Further researches on the efficacy of iintervention programmes that deliver messages about the harmful effects of smoking with support for smokefree policies are strongly recommended, to identify the most effective means and type of messages that should be delivered.

We found that females were more supportive for smoke-free policies compared to males, such a difference between the gender was consistent with the results reported by Chen at al. $2019^{11}$ and Erguda et al. $2008^{16}$ among youth in Hong Kong and Turkey, respectively. The norm of smoking among males is generally accepted by Malaysian society. ${ }^{19}$ Norm has been identified as one of the factors associated with smoking among adolescents in previous studies. ${ }^{10,20,21}$ This similar factors might be used to expound a higher likelihood of SFI support in public areas among youths schooling in urban areas, in which, majority of gazetted smoke-free localities are located in urban areas ${ }^{5}$ which may de-normalise smoking behaviour, as well as influence their perceptions toward SFP. However, our hypothesis needs to be tested in future studies through qualitative or quantitative studies.

In line with the finding reported by Lazuras et al. 2011, ${ }^{10}$ our study revealed that younger age group were less likely to support smoke-free in public areas compared to the older age groups. However, this is in contrast with the findings reported by Chen et al. 2019. ${ }^{11}$ We postulated that level of maturation and thinking capability might be among the influencing factors in which the older age groups might be more likely to appreciate the SFI in concern of their health.

The higher proportion and likelihood of support were found among those who have been taught in school on the danger of smoking. The findings are congruent with the studies among youth in Hong Kong and Greece. ${ }^{10-11}$ In addition, it also in line with the with previous research in adults. Students who had been taught in school might have better knowledge on the harmful effects of tobacco, therefore draw them towards any policies in line in their belief as posited by the health belief model. ${ }^{18}$ The finding suggested the integration of a specific module on the harm of tobacco into the curriculum to be considered under the MOE.

Although the previous study showed that respondents from higher smoking prevalence backgrounds and those exposed to SHS were less likely to support SFP in public areas, ${ }^{5}$ Our study showed that the level of support and likelihood of support for SFP in public areas was significantly higher among youths from Malay, and Bumiputra 
Sabah dan Sarawak, who reported a higher prevalence of smoking in this study. In addition, the proportion and likelihood of youths exposed SHS were more likely to support SFP in public areas. The finding indicated that youths react differently to SFP in public areas compared to Malaysian adults in which adults from Malay ethnics and those reported exposure to SHS were less likely to support SFP in public areas. ${ }^{6}$ which provide a better prospect for the prevention of SHS initiative in the future. However, more studies are required to elucidate and to understand the mechanism of higher support for SFP in public areas among those groups with higher smoking prevalence and SHS exposure in the country.

The study was not without limitation, and data obtained through self-administered, which might be over or under-reporting due to social bias. In addition, the cross-sectional study design can only enable the establishment of the association between the independent and dependent variables. However, the representative of the sample allows for the generalisation of finding to Malaysian youth. In addition, the anonymity of respondents' status might encourage the youths to enclose the information of their current status of smoking and other related information.

\section{CONCLUSION}

The level of support of smoke-free initiative in public areas was high among youths in Malaysia which offered the promising prospect to expand the SFP to more public areas in the future. However, measures to enhance the knowledge about the health hazards of SHS and tobacco smoking through various school programmes targeting those high-risk group as being identified in the current study is essential. This is to ensure the SFP in public areas will be widely accepted in the future.

\section{ACKNOWLEDGMENT}

We would like to thank the Director-General of Health Malaysia for his permission to publish this paper.

\section{REFERENCES}

1. Iribarren $\mathrm{C}$, Darbinian J, Klatsky $\mathrm{AL}$ \& Friedman GD. Cohort study of exposure to environmental tobacco smoke and risk of first ischemic stroke and transient ischemic attack. Neuroepidemiology. 2004; 23(1-2): 38-44.

2. Öberg M, Jaakkola MS, Woodward A, Peruga A, \& Prüss-Ustün A. Worldwide burden of disease from exposure to second-hand smoke: a retrospective analysis of data from 192 countries. The Lancet. 2011;377(9760): 139-146.

3. WHO. Who Framework Convention on Tobacco Control. 2003. [cited on 2020
Nov 18] Available from https://apps.who.int/iris/bitstream/handle/ 10665/42811/9241591013.pdf? sequence $=$ 1.

4. Government of Malaysia. Food act 1993: Control of tobacco product regulations. 2005. [cited on 2020 Nov 18] Available

from http://www.tobaccocontrollaws.org/ files/live/Malaysia/Malaysia\%20 \%20TC\%20Regs\%202004.pdf.

5. Lim KH, Teh CH, Mohamed MHN, Pan S, Ling MY, Yusoff MFM, Yusoff MFM, Hassan N, Baharom N, Dawam ND, Ismail N, \& Ghazali SM. Exposure to tobacco second hand smoke and its associated factors among non-smoking adults in smoking-restricted and non-restricted areas: findings from a nationwide study in Malaysia. BMJ

Open. 2018;8(1): e017203.

6. MOH. Health information today. 2000. Available from http://healthinfortoday.blogspot.com/2012 /04/young-doctors-club.html.

7. Hock LK, Li LH, Huey TC, Yuvaneswary V, Sayan P, Yusoff MFM, Kuay LK, Yn LM, Chee CK \& Mohd GS. Support for smoke-free policy among Malaysian adults: findings from a population-based study. BMJ Open. 2019;9(2): e020304.

8. Rosen LJ, Rier DA, Schwartz R, Oren A, Kopel A, Gevman A, Zeller M, \& Connolly G. Public support for smoke-free areas in Israel: A case for action. Health Policy. 2012;106(2): 161-168.

9. International Agency for Cancer Research [IARC] Working *Group on the Effectiveness of Smoke-Free Policies. Evaluating the effectiveness of smoke-free policies [IARC handbooks of cancer prevention, Vol. 13]. Lyon: WHO. 2009. [cited on 2020 Nov 18] Available from http://www.iarc.fr/en/pudbook13/ha ndbook13.pdf.18.11.2020.

10. Lazuras L, Rodafinos A, \& Eiser JR. Adolescents' support for smoke-free public settings: the roles of social norms and beliefs about exposure to secondhand smoke. Journal of Adolescent Health. 2011; 49(1): 70-75.

11. Chen J, Ho S, Leung L, Wang M, \& Lam T. Adolescent support for tobacco control policies and associations with tobacco denormalization beliefs and harm perceptions. International Journal of Environmental Research and Public Health. 2019;16(1): 147.

12. Lee S, Grana RA \& Glantz SA. Electronic cigarette use among Korean adolescents: a 
cross-sectional study of market penetration, dual use, and relationship to quit attempts and former smoking. Journal of Adolescent Health. 2014;54(6): 684690 .

13. Institute of Public Health. Adolescents tobacco and e-cigarette survey among Malaysian adolescents 2016. (TECMA): Institute of Public Health. Kuala Lumpur. 2016.

14. Jaine R, Healey B, Edwards R \& Hoek J. How adolescents view the tobacco endgame and tobacco control measures: trends and associations in support among 14-15 year olds. Tobacco Control. 2015;24(5): 449-454.

15. Veeranki SP, Mamudu HM. Determinants of adolescents' (11-17 years) support for smoke-free policies globally. Conference: 139st APHA Annual Meeting and Exposition. 2011.

16. Erguder T, Çakır B, Aslan D, Warren CW, Jones NR \& Asma S. Evaluation of the use of Global Youth Tobacco Survey (GYTS) data for developing evidence-based tobacco control policies in Turkey. BMC Public Health. 2008; 8(1): S4.

17. Cooper J. Cognitive Dissonance: Fifty Years of a Classic Theory. SAGE Publications Ltd. London. 2007.

18. Jones CL, Jensen JD, Scherr CL, Brown NR, Christy K \& Weaver J. The health belief model as an explanatory framework in communication research: Exploring parallel, serial, and moderated mediation. Health

Communication. 2015;30(6): 566-576.

19. Lim HK, Teh HC, Lim LH, Lau JK, Kee CC, Ghazali SM, Chan YY, Sabtu MY, Ismail H, Zaki N \& Thomas L. Smoking among secondary school students in Kota Tinggi, Johor, Malaysia-findings from a cross-sectional study. Asian Pacific Journal of Cancer Prevention. 2015;16(11): 4563-4570.

20. Lim KH, Ghazali SM, Kee CC, Rahman HA \& Mustafa AN. Perceived norms and smoking status among secondary school students in Kota Tinggi, Johor, Malaysia. International Journal of Public Health Research. 2012; 2(1): 85-92.

21. Echeverría SE, Gundersen DA, Manderski MT \& Delnevo CD. Social norms and its correlates as a pathway to smoking among young Latino adults. Social Science \& Medicine. 2015;124: 187-195. 